\title{
Regionalism in Two Southern States: an Exploratory Study of Intrastate Politicocultural Cleavages
}

\author{
Robert L. Savage \\ University of Arkansas, Fayetteville \\ John P. Price \\ Association of Arkansas Counties
}

Abstract: Regional patterms of politicocultural variation within Alabama and Arkansas are explored by $Q$-factoring a wide array of social, economic, and political data at the county level for each state. The results confirm that in each state there are two regions conforming to the proverbial distinction between the mountain South and the plantation South. Moreover, in each state a number of counties have emerged as a distinctly urban type. These three types are compared with the American subcultural patterms described In Elazar. The areas roughly conform to these subcultural patterns. Further, as predicted, the Moralistic orientation is more clearly delineated in an Arkansas region, the "Ozark," while the Traditionalistic and Individualistic patterns are stronger for two of the Alabama area types.

Although regional variations within the southern states have been widely recognized, those variations have received little systematic attention from political scientists beyond the usual nod to "mountain Republicanism" and, in some cases, the alignment of Democratic party factions along geographical lines. ${ }^{1}$ Yet, in his analysis of American federalism from the perspective of the states, Elazar argues that many intrastate political conflicts flow from differing subcultural orientations that are typically associated with constrasting settlement patterns of geographic regions within the states. ${ }^{2}$ Thus, southern states tend to be divided broadly in terms of mountain areas and plantation areas. More recently, major urban areas have emerged with features distinctive from either of these geographically-based regions. At the same time, there is a peculiarly "Southern" culture associated with an elitist politics fostered 
traditionally by racist rhetoric directed toward a population mass that is characteristically deprived of the economic wealth enjoyed in most other areas of the nation. The analysis reported here addresses this question of politicocultural variations in the South as exemplified by two states: one from the Deep South, Alabama, and the other on the southern periphery, Arkansas.

Two sets of hypotheses are at issue here. First, very broadly, are there distinctive politicocultural areas within these states which are at the same time common to both states? And, secondly, can differences between two states be predicted on the basis of their differing locations relative to the southern "core"? 3 Thus, the following hypotheses and corollaries are proffered:

1. There are three basic types of politicocultural areas in each state. (a) The basic types of politicocultural areas conform to wellrecognized regional and/or settlement patterns in the American South, i.e., the plantation South, the mountain South, and the urban South. (b) The basic types of politicocultural areas conform to the three major subcultural orientations described by Elazar, i.e., Traditionalistic, Moralistic, and Individualistic.

2. The distinctiveness of politicocultural areas within a state is related to the geographical location and peculiar historical development of the state. (a) Both the Traditionalistic and the Individualistic subcultures are more clearly delineated in Alabama (due to its location in the Deep South on the one hand and its earlier urbanization on the other.) (b) The Moralistic subculture is more clearly delineated in Arkansas (due to its closer proximity to the Greater West).

\section{Data and Methods}

In order to obtain a wide array of data comprehensive both in terms of being descriptive of social, economic and political characteristics of the population and in terms of geographic spread. county-level data were gathered for all counties in both states. Unfortunately, data for some attributes were available for one, but not the other, state. As these uncommon attributes are in some instances important and even unique indicators of political culture variations, however, they were retained for analysis. ${ }^{4}$

The dataset for each state was subjected to Q-factor analysis using the eigenvalue-one criterion to determine the number of 
factors to be extracted. ${ }^{5}$ While any criterion for such extraction is arbitrary, the decision to use this widely-recognized statistical test gives greater weight to arguments for the existence of the basic types of variation, particularly if the numbers conform to the predicted values.

Q-factoring of the datasets is mandated as the resultant factors cluster together those counties that have common patterns of variation and thus the $Q$-factors represent operationally-defined "politicocultural areas" within each state. To the extent that a factor is composed of more or less contiguous counties, that factor constitutes a "region." The factor score matrices present standardized values for each of the attributes across these basic types of politicocultural areas, thus allowing analysis of the distinctive features of each area.

While the larger, unique datasets provide the statistical information for most of the findings reported here, separate $Q$-factor analyses were also performed for each state using the 61 attributes common to both datasets. ${ }^{6}$ These analyses allow correlation of the typal arrays (factor scores) across types of counties for both states, thus permitting a test of the congruency of politicocultural areas between the states.

\section{Findings}

The factor analytic results confirm the existence of three distinct politicocultural areas both in Alabama and Arkansas. ${ }^{7}$ Moreover, for each state, as shown in Tables 1 and 2, two more or less contiguous regions distinguishing the "plantation" area from the "mountain" area emerged, as did a distinctive Urban County type. Thus, for Alabama, Factor I is the Black Belt Region clustering 24 southern counties with its 9 best representatives all from that portion of the state traditonally called "The Black Belt." Factor II is the Urban County with Jefferson County (Birmingham) as a virtually pure representative, and Factor III is the Northern-Wiregrass County with its best representatives all from the more mountainous areas of the North. This third factor groups the "Wiregrass" area, a tier of counties bordering the Florida Panhandle with the northern rather than southern counties.

In Arkansas, Factor 1 is the Ozark Region clustering counties largely in the northwestern and more mountainous areas of the 
state, Factor II is the Delta Region with its best representatives all from the Mississippi Delta area although the type includes most of the southeastern portion of the state, and Factor III is the Urban County. Thus, the basic politicocultural areas within these two southern states do conform to the hypothesized regional and/or settlement patterns that have generally been recognized in the past.

\section{Table 1 ALABAMA POLITICOCULTURAL REGIONS: Q-FACTOR MATRIX*}

FACTOR LOADINGS

County

Greene

Bullock

Lowndes

Sumter

Wilcox

Macon

Perry

Hale

Marengo

Conecuh

Choctaw

Monroe

Barbour

Pickens

Butler

Henry

Dallas

Clarke

Pike

Coosa

Crenshaw

Chambers

Autauga

Russell

\begin{tabular}{cccc} 
I & II & $\begin{array}{c}\text { III } \\
\text { Black }\end{array}$ & \multicolumn{3}{c}{$\begin{array}{c}\text { Northern- } \\
\text { Belt }\end{array}$} & Urban & Wiregrass & $\mathrm{h}^{2}$ \\
90 & 24 & 29 & 0.95 \\
87 & 27 & 37 & 0.97 \\
87 & 20 & 37 & 0.94 \\
86 & 26 & 39 & 0.96 \\
85 & 29 & 34 & 0.92 \\
84 & 30 & 25 & 0.87 \\
82 & 26 & 41 & 0.92 \\
79 & 20 & 43 & 0.86 \\
77 & 36 & 48 & 0.96 \\
75 & 24 & 59 & 0.97 \\
74 & 23 & 58 & 0.94 \\
74 & 27 & 59 & 0.97 \\
74 & 34 & 57 & 0.98 \\
72 & 28 & 59 & 0.94 \\
71 & 29 & 60 & 0.95 \\
71 & 29 & 60 & 0.96 \\
71 & 53 & 43 & 0.97 \\
70 & 31 & 62 & 0.98 \\
70 & 36 & 58 & 0.96 \\
70 & 20 & 64 & 0.94 \\
69 & 25 & 66 & 0.97 \\
65 & 32 & 65 & 0.94 \\
64 & 41 & 58 & 0.91 \\
60 & 54 & 47 & 0.88
\end{tabular}




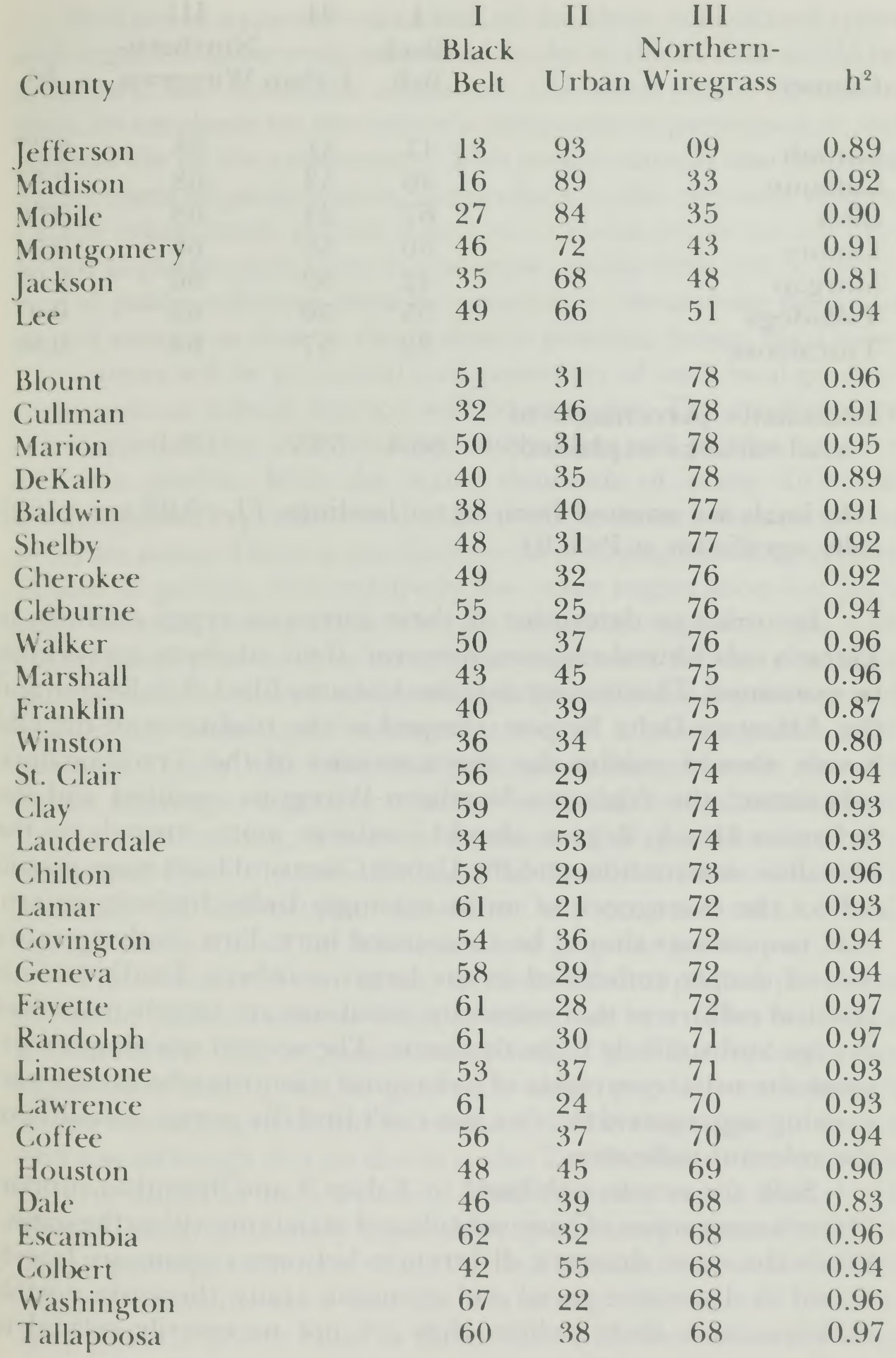


Etowah

Calhoun

Bibb

Elmore

Morgan

Talladega

Tuscaloosa

$\begin{array}{ll}47 & 51 \\ 46 & 53 \\ 67 & 24 \\ 60 & 38 \\ 42 & 59 \\ 55 & 50 \\ 39 & 57\end{array}$

$36.4 \quad 53.7$

93.1

Cumulative percentages of total variance explained:

* Decimals are omitted from factor loadings. FL $\geqslant 0.28$ are statistically significant at $\mathrm{P} \leqslant 0.01$.

In order to determine if these intrastate types conform to Elazar's subcultural variants, however, their attribute arrays must be examined. This is to say that the Alabama Black Belt Region and the Arkansas Delta Region, steeped in the traditions of the Old South, should exhibit the characteristics of the Traditionalistic subculture, the Alabama Northern-Wiregrass counties and the Arkansas Ozark Region should conform more strongly to the Moralistic orientation, and the Urban County of both states should reflect the emergence of an increasingly Individualistic pattern. Still, two caveats should be announced here. First, both states are indeed deeply embedded in the larger southern Traditionalistic political culture so that intrastate variations are largely matters of degree and unlikely to be dramatic. The second warning centers upon the usual complaint of behavioral scientists who must resort to using aggregate date: "we just can't find the purest measures of the relevant indicators."

Still, the results exhibited in Tables 3 and 4 tend to support Elazar's contention of basic subcultural variations within the states. While the more dramatic differences between regions are largely found in distinctive social and economic traits, there are notable differences in their politics that are not necessarily related to socioeconomic variations. 
Profiles of expected variations of the three subcultural types with regard to those traits measured by the available data would be as follows. The Moralistic subculture will stress public education given its emphasis on the citizen's obligation to participate in the political life of the community. This motive should also produce higher rates of participation, particularly in the electoral system. On the other hand, private solutions to social problems are preferred to public ones, thus, for example, public debt will be lower. And if public solutions must be resorted to, then those decisions should remain as close to the people as possible, hence, local revenue sources will be preferred and automony of such local government units as school districts will be stronger. The marketplace orientation of the Individualistic subculture will produce a very different profile. With the active demands of many different groups, public expenditures decisions will be more balanced across program areas. There is not likely to be a strong effort to involve citizens in politics, thus relatively low voter registration but high voter turnout among those who do bother to register. And with government perceived as simply an extension of the economic marketplace, it will seek revenues equally well from any source and will not shy from capital investment even if it means public indebtedness. Finally, efficiency and professionalism are more strongly prized, leading to a greater reliance on hierarchy and administrative decision making, hence less autonomy for specialized governments and fewer elected officials. The Traditionalistic subculture generally will fall between the other two on most measures although there should be noticeably less popular participation.

The evidence of conformity to these cultural prototypes by the intrastate politicocultural areas is mixed at best. The Moralistic profile fits the Ozark County rather well. There is very high voter registration and, given its generally older population, relatively strong commitment to public education. Moreover, public debt is very low although this no doubt is also a reflection of the extreme poverty found in such a county. And contrary to the model, the Ozark County is strongly dependent upon intergovernmental revenues, perhaps even more than the lack of economic wealth would suggest. But at the same time there is strong evidence of a desire to keep political power close to the people with the extremely large 
number of elected local officials and the stronger likelihood of school district tax autonomy. The Northern-Wiregrass County of Alabama does not conform so well. ${ }^{9}$ Still, there is the apparent tendency to avoid public dept and a strong self-reliance in revenue production. Beyond these traits, in both states these are the areas that reflect the most independence from partisan affiliations in voting. On more idiosyncratic measures note the relative resistance of the Ozark County to adopting federal food programs and the greater participation in litigation on welfare matters and the higher score of the Northern-Wiregrass County on the Index of Union Sentiment. ${ }^{10}$

The political attributes of the Urban County of both states tend to be very similar and generally conform to the Individualistic model. Public expenditures do tend to be more balanced across policy areas. Popular participation is low in terms of voter registration but in Arkansas (comparable data for Alabama is unavailable) those who register exhibit a strong likelihood of voting and are more partisan. Public indebtedness is high as predicted. However, the Urban County appears to be more self-reliant in obtaining public revenues but then such a county is much wealthier than other types in either state. And in both states there are relatively fewer elected local officials and public school districts have independent taxing power. Still, this suggests at least a greater reliance on hierarchy in government. 


\section{Table 2 \\ ARKANSAS POLITICOCULTURAL REGIONS: \\ Q-FACTOR MATRIX*}

\section{FACTOR LOADINGS}

County

Perry

Izard

Marion

Montgomery

Sharp

Newton

Van Buren

Fulton

Pike

Yell

Searcy

Cleburne

Franklin

Cleveland

Scott

Stone

Polk

Johnson

Randolph

Grant

Madison

Lawrence

Calhoun

Crawford

Logan

Baxter

Sevier

Clay

Carroll

Prairie

Howard
II

Orark Delta

91

91

88

87

87

86

84

81

80

78

78

78

78

77

77

77

76

76

76

74

73

72

72

71

71

70

70

70

69

68

67
26

29

27

32

29

39

39

40

44

41

47

45

44

55

39

47

41

45

44

48

45

53

58

46

46

34

50

55

45

60

53
III

Urban

$h^{2}$

12

0.91

14

0.93

27

31

19

19

32

36

36

42

28

39

40

20

38

35

47

43

40

38

29

39

22

47

50

56

41

38

47

0.92

0.96

0.88

0.92

0.95

0.94

0.95

0.96

0.91

0.96

0.96

0.95

0.89

0.93

0.97

0.96

0.93

0.93

0.83

0.95

0.90

0.95

0.95

0.92

0.91

0.94

0.90

0.90

0.94 
White

Boone

Independence

Little Rock

Pope

Lee

Phillips

Crittenden

St. Francis

Chicot

Monroe

Desha

Jefferson

Mississippi

Woodruff

Cross

Lincoln

Arkansas

Jackson

Poinsett

Drew

Lonoke

Lafayette

Miller

Ouachita

Columbia

Dallas

Hempstead

Bradley

Ashley

Nevada

Union

Craighead

Clark

Conway

Greene

Hot Spring
Ozark Delta Urban

$h^{2}$

$\begin{array}{llll}67 & 50 & 51 & 0.96 \\ 66 & 43 & 54 & 0.91 \\ 65 & 54 & 43 & 0.91 \\ 63 & 53 & 41 & 0.84 \\ 62 & 49 & 58 & 0.96\end{array}$

$41 \quad 86$

$25 \quad 85$

$31 \quad 83$

$43 \quad 83$

$40 \quad 82$

$48 \quad 81$

$47 \quad 80$

$32 \quad 78$

$32 \quad 77$

$56 \quad 75$

$49 \quad 75$

$60 \quad 75$

$45 \quad 71$

$52 \quad 69$

$54 \quad 69$

$56 \quad 69$

$58 \quad 68$

$65 \quad 67$

$41 \quad 67$

$48 \quad 66$

$53 \quad 66$

$58 \quad 66$

$60 \quad 65$

$56 \quad 65$

$40 \quad 65$

$62 \quad 64$

$45 \quad 63$

$46 \quad 63$

$51 \quad 62$

$60 \quad 60$

$58 \quad 59$

$55 \quad 56$ $\begin{array}{ll}17 & 0.93\end{array}$

$36 \quad 0.92$

$37 \quad 0.92$

$28 \quad 0.95$

$35 \quad 0.96$

$26 \quad 0.96$

$33 \quad 0.97$

$\begin{array}{ll}50 & 0.97\end{array}$

$46 \quad 0.90$

$26 \quad 0.95$

$37 \quad 0.95$

$19 \quad 0.96$

$48 \quad 0.93$

$42 \quad 0.93$

$40 \quad 0.93$

$39 \quad 0.94$

$36 \quad 0.93$

$23 \quad 0.93$

$57 \quad 0.94$

$47 \quad 0.89$

$46 \quad 0.93$

$33 \quad 0.87$

$39 \quad 0.94$

$38 \quad 0.89$

$49 \quad 0.83$

$37 \quad 0.94$

$56 \quad 0.91$

$52 \quad 0.92$

$40 \quad 0.88$

$53 \quad 0.91$
$57 \quad 0.92$

$50 \quad 0.93$ 
County

Washington

Sebastian

Garland

Pulaski

Benton

Saline

Faulkner

\section{Ozark Delta Urban}

$\mathrm{h}^{2}$

43

46

74

$37 \quad 52$

72

0.94

$41 \quad 48$

$07 \quad 55$

$60 \quad 42$

$54 \quad 52$

$55 \quad 56$

71

0.91

66

0.75

63

0.94

58

56

0.90

0.93

Cumulative percentages of total variance explained

\section{$\begin{array}{lll}40.2 & 73.9 & 92.3\end{array}$}

* Decimals are omitted from factor loadings. FL $\geqslant 0.26$ are statistically significant at $\mathrm{p} \leqslant 0.01$.

The Black Belt and Delta types do not appear to be so congruent in their political attributes as the Urban types but more so than is the case for Northern-Wiregrass and Ozark types. Educational expenditures take a high proportion of the total outlay in both the Black Belt County and the Delta County, a result that is not surprising with their youthful populations. On other matters of public finance mixed results occur. The Delta County is less dependent on intergovernmental revenues than expected while the Black Belt County exhibits more autonomy in school district taxation than predicted. And with regard to political partisanship Delta County voters seem less committed to the Democratic Party than those in the Black Belt counties.

In general, then, the congruence of the attributes of the empirically-determined politicocultural areas with Elazar's subcultural orientations is uneven. Still, these surface comparisons do provide some support for the second hypothesis and its corollaries. The Arkansas Ozark County does fit the Moralistic type much more strongly than its Alabama counterpart. To a lesser extent, as predicted, the Alabama Black Belt County is more congruent with the Traditionalistic subcult ure than the comparable Arkansas type. 


\section{Table 3 \\ TYPAL ARRAYS FOR ALABAMA POLITICOCULTURAL REGIONS: FACTOR SCORE MATRIX}

Attribute

$\%$ urban, 1970

$\%$ of popn. under 5 yrs. of age, 1970

$\%$ of popn. 18 yrs. and older, 1970

$\%$ of popn. 65 yrs. and older, 1970

Birth rate per 1000 popn., 1970

Death rate per 1000 popn., 1970

Death rate (under $1 \mathrm{yr}$.) per

1000 births, 1970

Death rate (under 28 days) per

1000 births, 1970

Population density, 1970

$\%$ non-white popn., 1970

$\%$ change in net migration,

1960-1970

\% change in Negro net migration,

1960-1970

\% foreign stock, 1970

$\%$ veteran status, 1970

\% born in different state, 1970

Median school yrs. completed, 1970

$\%$ of students in private elementary

and secondary schools, 1970

$\%$ of females who are high school

graduates 1970

$\%$ of males who are high school

graduates, 1970

$\%$ of persons $25 \mathrm{yrs}$. and older with

5 yrs. of school or less, 1970

$\%$ of persons $25 \mathrm{yrs}$. and older with

4 yrs. of high school or more, 1970

$\%$ of persons $25 \mathrm{yrs}$. and older with

4 yrs. of college or more, 1970
TYPAL ARRAYS

I

I I

III

Black

Belt

$-0.6$

$-0.4$

0.3

$-0.3$

$-0.2$

$-0.3$

0.5

$-0.1$

$-0.6$

2.5

$-1.8$

$-0.8$

$-0.0$

$-1.6$

$-0.6$

$-0.4$

$-0.6$

$-0.8$

$-0.6$

$-0.5$

0.3

$-0.2$

$-0.8$

$-0.0$

$-(0.5$

$-0.5$

$-0.6$

$-0.4$

$-0.5$

$-0.8$

$-0.8$

$-0.2$

0.7

$-(0.2$

$-0.3$

0.8

$-0.1$

0.2

$-0.8$

$-(0.8$

$-() .2$

0.7

$-0.1$

$-0.5$

$-0.4$

$-0.8$ 
$\%$ of students in elementary and

secondary schools who are

Negro, 1970

3.0

0.1

$-2.8$

$\%$ of owner-occupied housing

units, 1970

$\begin{array}{lll}0.1 & 0.3 & 1.4\end{array}$

$\%$ of occupied housing units with all plumbing facilities, 1970

$\begin{array}{lll}-1.7 & 1.6 & 1.3\end{array}$

$\%$ of occupied housing units with

home freezers, 1970

$\%$ of change in farm popn.,

1960-1970

Mean value of farm land per

$$
\text { acre, } 1969
$$

Harvested crop land as a percentage of total land area, 1969

$\%$ of farms with sales of $\$ 40,000$ and over, 1969

$\%$ of farms owned by

corporations, 1969

$\%$ of $\mathrm{mfg}$. establishments with 20-99 employees, 1967

\% of labor force employed in

government, 1970

$\%$ of labor force employed in mfg., 1970

$\%$ of labor force employed in

wholesale and retail trade, 1970

$\%$ of labor force employed in prof.

and managerial positions, 1970

$\%$ of females who are in labor

force, 1970

$\%$ of labor force working outside

county of residence, 1970

$\%$ of families with income less than

$\$ 3000,1970$

0.1

$-0.6$

0.9

$-2.5$

$-2.1$

$-1.4$

$-0.7$

0.2

$-0.1$

0.6

0.5

$-0.4$

$-0.6$

$-0.8$

$-0.4$

$-0.6$

$-0.9$

$-0.7$

$-0.7$

$-0.1$

$-0.3$

$-0.2$

$-0.2$

$-0.6$

$-0.3$

$-0.8$

0.8

$-0.4$

$-0.3$

$-0.3$

$-0.1$

$-0.6$

0.0

0.1

0.1

$-0.3$

$-1.3$

0.5

$\%$ of families with income of

$\$ 10,000-\$ 14,999,1970$

$\begin{array}{rrr}0.6 & -0.8 & -0.6 \\ -0.6 & -0.2 & -0.2\end{array}$


$\%$ of families with income of

$\$ 15,000-\$ 24,999,1970$

$\%$ of families with income of $\$ 25,000$ and over, 1970

$\%$ of direct general expenditures spent for education, 1967

$\%$ of direct general expenditures spent for highways, 1967

$\%$ of direct general expenditures spent for health \& hospitals, 1967 General debt outstanding, 1967 Property tax payments per capita, 1967

$\%$ of general revenue from intergovernmental revenue, 1967 $\%$ of general revenue from tax revenue, 1967

Number of elected local officials per 10,000 popn., 1967

Number of public school

systems, 1967

$\%$ of public school systems with property-taxing power, 1967 $\%$ of direct general expenditures spent for education, 1972

$\%$ of direct general expenditures spent for highways, 1972 $\%$ of direct general expenditures

spent for health \& hospitals, 1972 General debt outstanding, 1972 Property tax payments per capita, 1972

$\%$ of general revenue from intergovernmental revenue, 1972 $\%$ of general revenue from tax revenue, 1972

Index of Union Sentiment
$-0.6$

$-0.8$

0.5

$-0.0$

0.6

0.3

$-1.2$

$-0.5$

$-0.6$

$-0.9$

$-0.7$

2.7

$-2.0$

$-0.6$

0.2

$-0.3$

2.9

$-1.5$

$-0.7$

$-1.8$

1.5

0.8

0.1

$-1.5$

$-0.6$

$-0.9$

$-0.6$

0.8

1.0

0.5

0.8

$-0.4$

$-0.0$

$-1.0$

$-0.5$

$-0.7$

$-0.1$

$-1.3$

$-0.5$

$-2.7$

$-0.5$

0.6

$-0.1$

1.4

$-0.6$

0.1

$-0.6$

0.1

$-(0.2$

$-0.7$

$-0.9$ 


$\begin{array}{cccc} & \text { I } & \text { II } & \text { III } \\ \text { Attribute } & \text { Black } & & \text { Northern- } \\ \text { Belt } & \text { Urban } & \text { Wiregrass }\end{array}$

$\%$ of eligible white voters

registered, 1968

$\%$ of eligible black voters

registered, 1968

$\%$ of vote for Nixon, Presidential

Election 1968

$\%$ of vote for Wallace, Presidential

Election, 1968

$\%$ of vote for Nixon, Presidential

Election, 1972

$\%$ of vote for Sparkman, Senatorial

Election, 1966

$\%$ of vote for L. Wallace,

Gubernatorial Election, 1966

$\%$ of vote for Allen, Senatorial

Election, 1968

$\%$ of vote for $\mathrm{G}$. Wallace,

Gubernatorial Election, 1970

$\%$ of vote for Sparkman, Senatorial

Election, 1972

$\%$ of vote for G. Wallace,

Gubernatorial Election, 1974

$\%$ of vote for Gallion, General

Election, 1966

$\%$ of vote for M. T. Allen, General Election, 1966

$\%$ of vote for Baggett, General

Election, 1966

$\%$ of vote for Beard, General

Election, 1966

$\%$ of vote for L. Wallace, Dem

Run-off, 1966

$\%$ of vote for M. T. Allen, Dem.

2.1

0.0

1.5

0.4

$-0.4$

$-1.1$

$-0.4$

$-0.1$

0.0

2.0

$-0.5$

0.4

2.2

1.0

0.6

0.3

0.9

0.1

$-0.1$

0.1

2.2

$-0.6$

0.2

2.8

0.2

0.5

1.0

1.5

0.8

1.5

0.7

0.6

1.5

0.9

0.4

1.8

0.7

0.2

1.0

0.4

0.7

$-0.0$

$-0.3$

Run-off, 1966

0.6

0.5

0.4

$\%$ of vote for Baggett, Dem.

Run-off, 1966

1.0

0.5

$-0.2$ 
Attribute

$\%$ of vote for Beard, Dem.

$$
\text { Run-off, } 1966
$$

$\%$ of vote for Gallion, Dem.

Primary, 1966

$\%$ of vote for $\mathrm{G}$. Wallace, Dem.

Run-off, 1970

$\%$ of vote for CA on literacy test, 1965

$\begin{array}{ccc}\begin{array}{c}\text { I } \\ \text { Black } \\ \text { Belt }\end{array} & \text { II } & \begin{array}{c}\text { III } \\ \text { Urban }\end{array} \\ & \text { Wiregrass }\end{array}$

$\begin{array}{ccc}0.9 & 0.4 & 0.3 \\ 0.7 & 0.4 & 1.0 \\ -0.3 & -0.2 & 1.4 \\ 0.2 & 0.9 & 1.4\end{array}$




\section{Table 4 \\ TYPAL ARRAYS FOR ARKANSAS POLITICOCULTURAL REGIONS: \\ FACTOR SCORE MATRIX}

Attribute

\% urban, 1970

$\%$ of popn. under 5 yrs. of age, 1970

$\%$ of popn. 18 yrs. and older, 1970

$\%$ of popn. 65 yrs. and older, 1970

Median age, 1972

Birth rate per 1000 popn., 1970

Death rate per 1000 popn., 1970

Death rate (under $1 \mathrm{yr}$.) per

1000 births, 1972

Death rate (under 28 days) per 1000 births, 1972

Population density, 1970

\% nonwhite popn., 1972

\% change in net migration,

$$
\text { 1960-1970 }
$$

\% change in Negro net migration, 1960-1970

\% foreign stock, 1970

\% veteran status, 1970

\% born in different state, 1970

Median school years

completed, 1970

$\%$ of students in private elementary and secondary schools, 1970

$\%$ of females who are high school graduates 1970

$\%$ of males who are high school graduates, 1970

$\%$ of persons 25 yrs. and older with 5 yrs. of school or less, 1970
TYPAL ARRAYS

I

II

I I I

Ozark Delta Urban

$-2.3$

0.9

2.7

$-0.4$

$-0.4$

$-0.7$

1.0

0.5

1.2

0.0

$-0.6$

$-0.5$

0.5

$-0.4$

0.0

$-0.4$

0.0

$-0.5$

$-0.1$

$-0.5$

$-0.6$

$-0.2$

0.2

$-0.7$

$-0.2$

$-0.2$

$-0.6$

$-0.8$

$-0.7$

$-0.2$

$-1.4$

2.4

$-2.3$

0.2

$-3.3$

1.3

$-0.4$

$-2.0$

0.3

$-0.5$

$-0.8$

$-0.6$

0.1

$-0.3$

0.8

$-0.2$

$-0.9$

0.7

$-0.3$

$-0.4$

$-0.1$

$-0.5$

$-0.7$

$-0.5$

$-0.2$

$-0.3$

1.3

$-0.3$

$-0.3$

1.3

$-0.4$

0.4

$-1.3$ 
$\%$ of persons 25 yrs. and older with 4 yrs. of high school or more, 1970

$\%$ of persons 25 yrs. and older with 4 yrs. of college or more, 1970

$\%$ of students in elementary and secondary schools who are Negro, 1970

$\%$ owner-occupied housing units, 1970

$\%$ of occupied housing units with all plumbing facilities, 1970

$\%$ of occupied housing units with home freezer, 1970

Medical doctors per 1000

$$
\text { popn., } 1972
$$

Dentists per 1000 popn., 1972

General hospital beds per

1000 popn., 1972

\% change in farm popm., 1960-1970

Mean value of farm land per

$$
\text { acre, } 1969
$$

Harvested cropland as a percentage of total land area, 1969

$\%$ of farms with sales of $\$ 40,000$ and over, 1969

$\%$ of farms owned by corporations, 1969

$\%$ of mfg. establishments with 20-99 employees, 1967

$\%$ of labor force employed in government, 1970 $\%$ of labor force employed in mfg., 1970

$\%$ of labor force employed in wholesale and retail trade, 1970
$-0.5$

$-1.6$

3.0

1.6

0.0

0.3

$-0.7$

0.8

0.6

$-0.7$

$-0.6$

$-0.8$

$-0.5$

$-0.7$

$-0.5$

$-0.7$

$-0.5$

$-0.3$

$-3.8$

$-0.7$

0.6

$-0.2$

$-0.6$

2.2

$-0.4$

$-0.5$

0.3

$-0.7$

$-0.6$

$-0.6$

$-0.6$

$-0.1$

$-0.2$

$-0.4$

0.3

$-0.1$

$-0.2$

$-() .3$

$-0.3$ 
\% of labor force employed in professional and managerial positions

\% of females who are in labor force, 1970

\% of labor force working outside county of residence, 1970 \% of workers using public transportation 1970

$\%$ of families with income less than $\$ 3000,1970$

$\%$ of families with income of $\$ 10,000-14,000,1970$

$\%$ of families with income of $\$ 15,000-24,999,1970$ $\%$ of families with income of $\$ 25,000$ and over, 1970 Number of radio stations per 10,000 popn., 1972

Television coverage from outof-state, 1972

$\%$ of direct general expenditures spent for education, 1967 $\%$ of direct general expenditures spent for highways, 1967 $\%$ of direct general expenditures spent for health \& hospitals, 1967 General debt outstanding, 1967 Property tax payments per capita, 1967

$\%$ of general revenue from intergovernmental revenue, 1967 $\%$ of general revenue from tax revenue, 1967

Number of elected local officials per 10.000 popn., 1967

Number of public school systems, 1967

$-0.3$

$-0.2$

$-0.5$

0.4

$-0.3$

$-0.2$

0.5

$-0.7$

$-0.8$

0.4

0.3

$-1.4$

$-0.6$

$-0.4$

$-0.6$

$-0.6$

$-0.5$

$-0.5$

$-0.7$

$-0.7$

$-0.5$

$-0.6$

$-0.5$

$-0.5$

$-0.7$

$-0.8$

0.8

1.1

$-0.1$

$-0.1$

$-0.6$

$-0.7$

$-0.4$

$-0.8$

$-0.3$

$-1.1$

$-0.5$

0.2

$-0.3$

0.6

1.1

1.3

0.4

$-0.7$

$-0.3$

0.2

0.4

6.0

$-1.4$

$-0.5$

$-0.7$

$-0.7$ 
$\%$ of public school systems with property-taxing power, 1967

$\%$ of direct general expenditures spent for education, 1972

$\%$ of direct general expenditures spent for highways, 1972

$\%$ of direct general expenditures spent for health and

$$
\text { hospitals, } 1972
$$

General debt outstanding, 1972

Property tax payments per

$$
\text { capita, } 1972
$$

$\%$ of general revenue from intergovernmental revenue, 1972 $\%$ of general revenue from tax revenue, 1972

Average millage, 1971

Incidence of AFDC recipients, 1972 Incidence of OAA recipients, 1972 Incidence of fair hearing by State Dept. of Public Welfare,

\section{8-1969}

Speed of adoption of federal food distribution programs

$\%$ of voter turnout, General

Election, 1972

$\%$ of eligible voters registered, 1970

$\%$ of eligible voters registered, 1972

$\%$ of vote for Nixon, Presidential

Election, 1968

$\%$ of vote for Wallace, Presidential

Election 1968

$\%$ of vote for Nixon, Presidential

Election, 1972

$\%$ of vote for Bumpers,

Gubernatorial Election 1970

$-0.1$

1.1

$-0.6$

$-0.4$

$-0.8$

$-0.3$

$-1.7$

$-0.1$

$-0.4$

2.0

1.4

1.1

0.6

$-(0.8$

$-0.2$

0.1

0.1

0.7

0.8

1.2

$-1.0$

0.8

$-0.4$

1.5

0.1

0.6

$-0.2$

$-0.7$

$-0.7$

$-0.9$

1.2

$-0.8$

0.7

0.7

1.1

1.7

1.2

0.3

2.0

1.0

0.4

0.5

$-1.3$

0.1

1.2

$\%$ of vote for Fulbright, Dem.

Primary, 1968

0.8

0.9

1.2

0.2

0.7

0.6 


$\begin{array}{ccc}\text { I } & \text { II } & \text { III } \\ \text { Ozark } & \text { Delta } & \text { Urban }\end{array}$

\% of vote for Faubus, Dem.

Primary, 1970

$\%$ of vote for Riley, Dem.

Prinary, 1970

$\%$ of vote for Bumpers, Dem.

Primary, 1972

$\%$ of vote for Pryor, Dem.

Primary, 1972

$\%$ of vote for Bumpers, Dem.

Primary, 1974

$\%$ of vote for Pryor, Dem.

Primary, 1974

$\%$ of vote for Faubus, Dem.
0.5
0.9
1.1

$-() .5$

0.5

0.1

0.5

0.6

1.4

0.1

0.3

0.4

1.0

0.3

1.3

Primary, 1974

$\%$ of vote for Purcell, Dem.

Primary, 1974

$\%$ of vote for Brandon, Dem.

Primary, 1974

$\%$ of vote for proposed

Constitution, 1970

$\%$ of vote for CA to permit private
0.2
0.7
0.5

0.6

0.2

$-0.6$

0.6

1.7

$-0.3$

$\begin{array}{lll}0.1 & -0.6 & 0.8\end{array}$

$-0.4$

0.3

1.1

contracting for state printing, 1974 $\%$ of vote for CA to increase salaries

of state officials, 1974

\% of vote for CA to increase salary

limits for county officials, 1974

\% of vote for CA to allow the

legislature to set maximum

interest rates, 1974

$-0.1$

0.7

1.1

$-0.4$

0.9

0.6

$-0.1$

0.9

0.7

$-0.5$

$-0.2$

$-0.4$

These assertions are given further support by the stronger, purer factor loadings of the better representatives of the Arkansas Ozark and Alabama Black Belt Counties. And while the Urban County as a type in both states fits the Individualistic model, the factor loadings of the better Alabama representatives are much stronger than those in Arkansas.

These comparisons are not, of course, too very rigorous. To provide a more rigorous comparison, correlations were computed 


\section{Table 5}

\section{INTERTYPAL CORRELATIONS FROM FACTOR SCORE MATRICES OF 61 MATCHED ATTRIBUTES FOR ALABAMA AND ARKANSAS COUNTIES*}

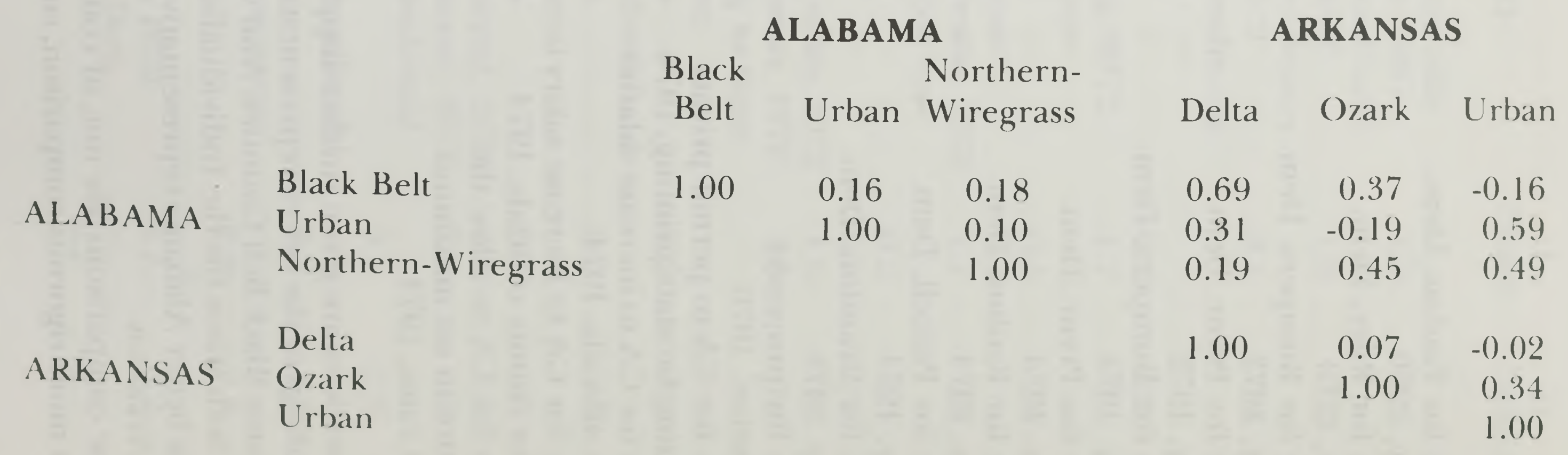

* The measure of correlation is the Pearsonian $\mathbf{r}$. 
for the factor score arrays for three-factor solutions of reduced data matrices of 61 common attributes for each state. Table 5 , somewhat contrary to the visual comparison largely of political attributes, shows that the Black Belt and Delta Counties are more similar than the two Urban Counties. However, many of the attributes lost from analysis due to the reduced data bases are political attributes. It comes as no real surprise that these types of counties retain much of the socioeconomic structure that comprises the contemporary (and past) popular image of the Old South.

\section{Conclusion}

The hypotheses that provoked this line of inquiry all received at least modest support. The results do suggest basic lines of similar politicocultural cleavages at work in two separated southern states. Still, one might ask, do these cleavages contribute to an understanding of contemporary political conflicts? For the most part the data used here do not speak to that point. To be sure, the differences among the areas in Presidential contests as shown in Tables 3 and 4 is clearly evident but those differences may simply reflect in many cases the "friends and neighbors" syndrome so familiar to students of Southern electoral politics.

The answer is that the cleavages uncovered here merely provide a base for further explorations. Two such areas of research would be the impact of these politicocultural areas upon electoral results, as mentioned above, and upon legislative behavior. If commonalities and differences among voters, legislators, or any other state political actors are to be examined along regional or politicocultural lines, then those analyses should be in terms of regions or political cultures and not arbitrary cartographical distinctions as has so often been done in the past.

But while this type of analysis may help to unravel some old mysteries, it may also reveal new mysteries. An example of this is the electoral support given to George Wallace in presidential and/or gubernatorial campaigns in these areas. Not surprising to most would be the lower levels of voting support that he received in the Urban County of either state and in the Ozark County, nor the strong support he garnered in 1968 in Arkansas' Delta region. But 
in Alabama his strongest support has been from the NorthernWiregrass area and he has fared least well in the Black Belt region. One explanation well may be that in his home state of Alabama, his populist appeals have touched a responsive chord in more Moralistic areas, while his early disregard of racist appeals did not endear him to Black Belt voters. Then, as he turned to such appeals, voters in the Black Belt were increasingly black. The opposite results obtained in Arkansas politicocultural areas, at least in part, because citizens there were much less aware of the evolution of Wallace's policy stand. Of course, data of a very different sort would be required to validate this explanation.

In any event, this study is an exploratory one. Similar research in the future should expand in two directions. The first of these is spatial. Other states must be examined in the same way as Alabama and Arkansas, which may not be sufficiently indicative of the South, let alone the nation.

The second direction is temporal. If cultural differences are involved, then these regional developments are rooted in history. Moreover, the Urban County as a distinct political subculture in the American South is a relatively recent development. Quantitative historical analysis of regionalism in the American states might well offer new insights into the movement and evolution of political culture and perhaps even open our eyes to the future. 
Acknowledgments: This is a revised version of a paper orginally presented at the Annual Meeting of the Southwestern Political Science Association, Dallas, Texas, A pril 1977. The authors wish to thank Kenneth D. Bailey, University of Arkansas, and Raymond B. Wells, Auburn University at Montgomery, for granting access to their unpublished data files. Also, much thanks to Lewis Leslie and Connie Holt for their assistance beyond the proverbial call in data preparation.

1. See, e.g., V. O. Key, Jr., Southern Politics in State and Nation (New York: Alfred A. Knopf, 1949).

2. Daniel J. Elazar, American Federalism: A View From the States, Second Edition (New York: Thomas Y. Crowell, 1972).

3. On core areas within geographical regions, see generally David E. Sopher, "Place and Lexation: Notes on the Spatial Patterning of Culture, "Social Science Quarterly, 53 (September 1972), 331-332; and as applied specifically to the American states, Robert L. Savage, "Patterns of Multilinear Evolution in the American States," Publius, 3 (Spring, 1973), 94-97.

4. Tables 3 and 4 provide, respectively, listings of the 94 attributes used for Arkansas counties and the 82 attributes for Alabama counties.

5. Varimax rotations were used for all factor analyses; for further information on factor analytic options see R.J. Rummel, Applied Factor Analysis (Evanston, Illinois: Northwestern University Press, 1970).

6. The factor analytic results for these two smaller data matrices are not reported here but may be obtained from the authors upon request.

7. Using the eigenvalue-one criterion actually resulted in a four-factor solution for Arkansas. However, as no county had its highest loading on the fourth factor, the decision to generate a three-factor solution seems fully warranted.

8. No attempt is made here to present a systematic analysis of the complete typal profiles. However, for such an analysis for one of these states, Arkansas, see Robert L. Savage and Richard J. Gallagher, "Politicocultural Regions in a Southern State: An Empirical Typology of Arkansas Counties," Publius, 7 (Winter, 1977), $91-105$.

9. The voter registration data is no test here as most Alabama counties in 1968 had $100 \%$ or more white voter registration. Perhaps these data only show that more accurate (honest?) rolls were kept in the Urban County.

10. The Index of Union Sentiment was derived by the senior author from data provided by Donald B. Dodd of Auburn University at Montgomery. The index reflects support given to the Union cause during the Civil War. 